\title{
Prospective mathematics teacher preparation: exploring the use of service learning as a field experience
}

\author{
Christa Jackson ${ }^{1 *}$, Margaret Mohr-Schroeder ${ }^{2}$, Maureen Cavalcanti ${ }^{2}$, Shelby Albers ${ }^{2}$, Katherine Poe ${ }^{2}$, \\ Ashley Delaney ${ }^{1}$, Emma Chadd $^{2}$, Mollie Williams ${ }^{2}$ and Thomas Roberts ${ }^{2}$
}

*Correspondence:

jacksonc@iastate.edu

${ }^{1}$ School of Education,

lowa State University, 1688

Lagomarcino Hall, Ames, IA 50011, USA

Full list of author information is available at the end of the article

\begin{abstract}
The See Blue Mathematics Clinic provides prospective teachers an authentic teaching environment via a service learning experience. In this qualitative study, the authors examine how a service learning course prepares prospective secondary mathematics teachers $(n=55)$ to teach students who struggle in mathematics. Data collected from reflection essays and interviews revealed the impact the service learning experience had on prospective secondary mathematics teachers and how it notably influenced their instruction. The results of this study add to the growing evidence for teacher preparation programs to create additional field experiences to better prepare future teachers.
\end{abstract}

\section{Introduction}

Perhaps the most traditional and iconic component of university teacher preparation programs in any discipline is experiential education (i.e., field experience), which is considered one of the most important and powerful components of teacher education programs [24]. Field experiences provide teacher candidates an understanding of the values, cultures, and styles of learning and school communities and are typically composed of student teaching, practicum experiences, community service, and service learning [4].

In most traditional teacher education programs, the field-based experiences are designed to socialize prospective teachers into the school setting [8]. Field experiences range from brief, observation-based practicums to extensive, in-depth internships that require additional practice of pedagogical knowledge under supervision of an experienced teacher. The most common field experience is student teaching, which traditionally includes observation and practiced application of instruction as a part of a semester-long course [21]. Although the prospective teacher has opportunities to implement instructional strategies, engage students in discourse, and "practice" instructional styles during the field-based experiences, they are under the direction and supervision of their cooperating teacher. In other words, the prospective teacher adheres to the preestablished classroom rules, procedures, and curriculum, and follows the lead of the 
cooperating teacher. In essence, the prospective teacher engages in an apprenticeship model where the main beneficiary of this experience is the prospective teacher.

However, some teacher education programs have transitioned to a service learning approach for their experiential education component. While not an explicit focus of this paper, it is important to note that service learning has mutual benefits for both the individual who is providing the service as well as the person and/or community receiving the service, which is substantially different from traditional practicum and student teaching experienced by most prospective mathematics teachers [48]. Specifically, "service learning is a pedagogical approach in which students learn and develop through active participation in thoughtfully organized service experiences that meet actual community needs" [11], p. 28). Therefore, as prospective teachers participate in service learning, they actively engage in and reflect on the service experience $[6,11]$.

Although service learning has been advocated in many teacher education programs (diversity, social studies, early childhood, literacy, special education, physical education), mathematics education programs have traditionally not taken advantage of this type of experiential education [48]. In this study, we examine how a service learning course prepares prospective secondary mathematics teachers to teach students who struggle in mathematics.

\section{Literature review}

\section{Traditional experiential education}

Field experiences, especially those conducted early in teacher education preparation programs, are generally seen as beneficial for prospective teachers (PTs), generating outcomes of increased enthusiasm for teaching and future methods courses as well as an improved and clarified understanding of the PT's decision to become a teacher [5, 7, 9, 30, 43]. In fact, new teachers often point to their field experiences as the most influential and valuable portions of their teacher preparation [30]. Brannon and Fiene [10] suggest this is because PTs have opportunities for first-hand experience to work through real problems and interact with students. Field experiences are far from perfect though.

It is true that logging numerous hours of observation for field experience within the actual classroom environment as a PT can be helpful in the preparation process. However, when student teachers are not cognitively prepared to learn from experiences in the field, they sometimes view the field experience as an off-campus activity as opposed to on-the-job training, and believe that the field experiences do not provide 'real teaching experiences'. [25]

When looking at the field experience component as a whole, it is difficult to establish consistency regarding the quality of the field experience among all PTs, including the quality of participation by and mentoring role of the cooperating classroom teacher [30]. Alsup et al. [5] noted,

when there is a great deal of inconsistency between pre-service teacher experiences in the field and instruction provided in the methods classroom, young teachers will often opt either to enact practices they have experienced themselves and liked as students, or to use practices that mentor teachers in the schools promote because those teachers are currently in the trenches, unlike their university professors. (p. 338) 
The absence of a strong field experience can be detrimental to a future educator as well as the future students in the classroom of said educator, especially since "what students learn is directly related to what and how teachers teach" [21]. More notably "field experiences can lack fullness as authentic experiences" [5], p. 339). In even the best instances of PTs and cooperating teacher relationships, the PT is still a visitor in a classroom and not the overall coordinator of what is taught within its walls [5]. Thus, traditional field experiences do not allow PTs to fully operate in the role of the educator and are rated low in quality in an environment where quality over quantity of field experience should be the main concern [43].

\section{Service learning}

A majority of teacher education programs provide service learning opportunities to prospective teachers as part of their experiential experiences [2]. For example, LaMaster [30] describes a service learning program for physical education prospective teachers. The high school principal contacted the teacher education department at a local university and collaborated on ways to improve the curriculum. The high school teachers were frustrated and wanted to increase students' motivation and excitement. Both the teacher educators at the university and the teachers at the high school decided to have the prospective physical education teachers teach small groups of students. The prospective teachers reported this experience helped prepare them to be better teachers, and the high school teachers expressed that the level of their students' motivation and participation increased.

Similarly, Baldwin et al. [8] incorporated service learning with prospective physical education teachers and prospective literacy teachers. The prospective teachers participated in service learning settings different from their own backgrounds. One of the goals of the service learning project was for the prospective teachers to identify their own personal biases of working with students from diverse backgrounds. The teacher educators and the schools mutually collaborated on the service learning project. The prospective teachers planned and taught oral-history lessons with a literacy component. These lessons extended the oral-history project the students were learning. The motor-skills program service learning involved the prospective teachers working with students on their motor skills such as football, dance, and stepping. Prior to the service learning experience, the majority of the prospective teachers had negative preconceptions of students in underserved communities. After the service learning experience, the prospective teachers learned the importance of having high expectations and listening to their students.

Several empirical studies on service learning in the disciplines of physical education, multicultural education, literacy, social studies, and middle level education identify the importance of reflection in learning $[8,46]$ and report the prospective teachers' valuing of authentic experiences [30, 41, 46]. However, limited research on service learning in mathematics education exists.

So what can be done by teacher education programs within universities to increase the level of preparedness of PTs in addition to field experience? We propose that a course situated in service learning, an experiential experience involving "achievement of curricular goals through authentic school-based experiences” [8], p. 316) in an informal learning environment, will better equip aspiring teachers to handle the challenges of 
educating a classroom of students, including those students who are identified as struggling in mathematics. These nontraditional experiences can help provide PTs with an opportunity to engage and explore new ideas in other classrooms that they may not normally have in traditional field experiences. Nontraditional field experiences in informal learning environments are often with smaller groups of students and low stakes, providing a safer and more comfortable environment in which PTs can authentically engage [25].

Given the right environment, using an alternative or nontraditional field experience would allow PTs more opportunities to plan for teaching and to work with students [20]. For example, an informal learning environment provides the opportunity for PTs to really hone in on and practice instructional methodologies in real, contextual situations $[27,28,32]$. The more a PT works hands on with students, the more likely it is that their confidence in teaching will increase [10]. Working in a nontraditional environment can have a tremendous impact on PTs' ability to learn about and practice unique and authentic strategies in the field [27], and the PTs often cite these experiences as the most beneficial learning experiences in their teacher preparation program [28].

Service learning supports learning through providing rich interactions among students and engagement with authentic learning [35]. Although service learning may limit and narrow the scope of a field experience, it provides an opportunity for prospective teachers to connect academic learning to the service experience through practice [39]. With respect to the PTs' environment for this study, the community service entails activities as a means to gain real-world knowledge about content, presentation, and application. This environment provides an opportunity outside of the traditional practicum setting where PTs are required to apply content and pedagogical knowledge that has not prior been prepared through lesson and instructional planning, as is done for classroom instruction.

\section{Theoretical framework}

We draw on Cone and Harris' [13] service learning framework for our study. Cone and Harris situate their framework in Paulo Freire's critical pedagogy and Dewey's and Kolb's work with experiential learning. The six stages of Cone and Harris' [13] framework include (a) learners, (b) defining the task cognitively and pragmatically, (c) experiences, (d) critical reflection, (e) mediated learning, and (f) learners with newly integrated concepts. Cone and Harris' framework appears to address each stage as having temporal order, where for instance, experience precedes critical reflection, and critical reflection precedes mediated learning. For our study, we adapted Cone and Harris' [13] framework of six-stage lens model for service learning to examine how prospective mathematics teachers teach students who struggle in mathematics. We argue that the stages are more fluid as the learners experience them. Therefore, we contend the stages are integrated throughout the service learning experience (see Fig. 1). More specifically, the PTs and the students who struggle in mathematics are both experiencing aspects of service learning, and both develop agency through their mediated learning experiences from the situated learning environment and critical reflection.

The situated learning environment is established in an authentic activity where the task is defined cognitively and pragmatically; it is through this authentic activity that 


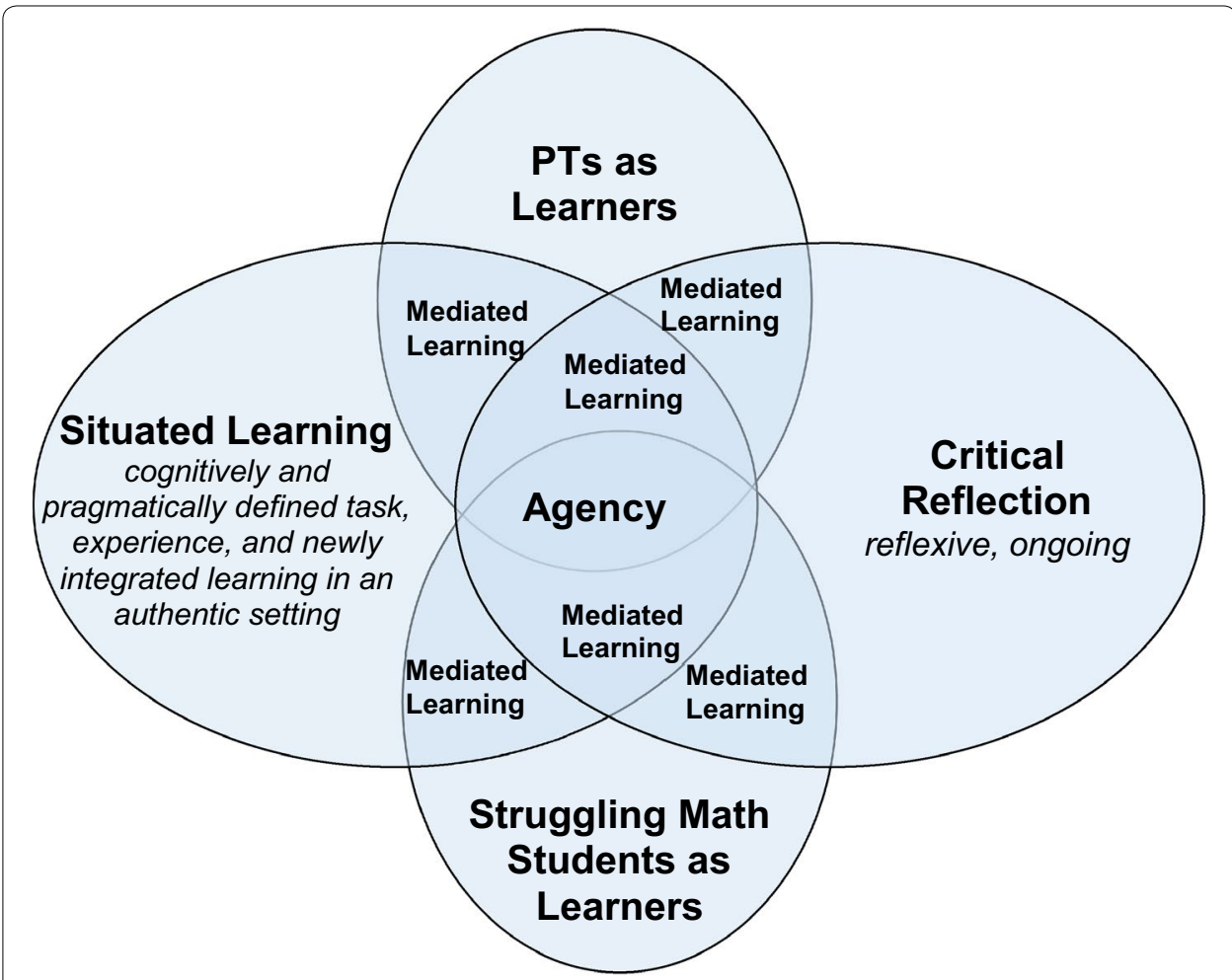

Fig. 1 PTs' lens model for service learning (adapted from [13])

learning becomes more contextualized [27]. For example, the PTs engage in the cognitively and pragmatically defined task by instructing students who struggle in mathematics in an authentic setting. Struggling mathematics students seeking after-school instruction from PTs is an authentic experience that teachers experience in their practice, but may not have the opportunity to experience in their practicum. Furthermore, the school building setting provides an authentic and realistic setting of individualized instruction not otherwise experienced through tutoring outside of the school or whole group instruction in the classroom. The "work of high cognitive demand and eliciting and responding to students" that PTs engage in directly occurs outside the university setting [36]. These experiences perpetuate service learning in both opportunity for services teaching and critical reflection about the experience. These opportunities for critical reflection not only enrich PTs' opportunities for pedagogical and content learning, but also strengthen support between peer PTs.

Agency has been purposefully placed at the intersection of all of the elements in our adapted framework. The literature on agency does not show how mediated efforts in a service learning course impact PTs who are working with students. However, research documents connections between agency and elements of service learning that have been identified as effective in the literature. For example, Ahearn's [3] work relates to conceptualizations of agency related to language. Based on the way PTs and students interact, they co-construct meanings of the experience and of the learning of mathematics through the tutoring experience situated in a school context [3]. Felton and Koestler [22] 
examined the relationship between critical reflection and agency in mathematics education, highlighting the importance of PTs making informed decisions that supports students' learning. This connection between critical reflection and agency is seen through the emphasis on acting for change in response to previous actions and established assumptions in education to improve student outcomes. Therefore, mentoring, shared learning [44], and mutual benefits [37] arise as they continue through the process. Swick [44] further suggests that when "teachers see themselves as builders of learning communities" (p. 263) the greatest impact of the experience on learners occurs.

For the purpose of this study, we define critical reflection as

a process of constantly analyzing, questioning, and critiquing established assumptions of oneself, schools, and the society about teaching and learning, and the social and political implications of schooling, and implementing changes to previous actions that have been supported by those established assumptions for student learning and a better schooling and more justice society for all children. [33]

Critical reflection as a process can be further classified as one that is reflexive in nature. Such a classification is supported by Liu's definition in reference to the process being constant. The reflections are both implicitly and explicitly defined at various times throughout the service learning course. They are reflexive in that thoughts, beliefs, and practices are reflected upon, discussed, applied and then reflection occurs again. Four specific aspects of the critical reflection include (a) planned opportunities [40], (b) structured reflection and extensive time in the experience [38], (c) critical reflection on current educational practices and their own teaching [4], and (d) reflective discussions and learning activities as part of the experience to help learners make connections [16]. These components are highlighted in PTs' coursework and tutoring sessions in the service learning course.

The overall focus on closing the gap between theory and practice is upheld in the adapted framework. Our framework supports Cone and Harris' [13] considerations for the personal and intellectual growth of student and community. We apply these considerations in the following ways: intellectual growth related to pedagogical and content knowledge of learners; personal growth related to critical reflection and agency; a focus on student and community as seen through the learners; and how the service learning experience is mediated to ultimately support positive outcomes.

We know that field experiences are important to all PTs and their path to becoming a teacher. Through our research, we know that through these alternative field experiences, PTs engage in low stakes, and authentic learning settings are comparable and often times more meaningful than traditional field experiences [28]. This also applies to our theoretical framework, where such a focus supports the assertion that mutuality and reciprocity among the campus and community, in this case the service learning course and school site, respectively, are the cornerstones to service learning [47].

\section{Methods}

This qualitative study involved both naturalistic inquiry and a phenomenological approach where the "lived experience" of the PTs were considered with respect to their participation in a service learning course $([15,34,42]$. In this study, we used qualitative 
methods [34] to examine how a service learning course prepares prospective mathematics teachers to teach students who struggle in mathematics. Using Denzin's [18] interpretive process, we focused on the lived experiences of the participants in the course in order to explore their growth through their interactions with middle and high school students. This approach allowed us to not only generate meaning from their growth in skill sets, but also to understand their experiences through emotional events that caused epiphanies, challenged mindsets, and resulted in joys [18].

Furthermore, in this qualitative study, we examined how a service learning course prepares prospective mathematics teachers to teach students who struggle in mathematics. The service learning course examined in this study is the See Blue Mathematics Clinic, a course designed by instructors at a large public university in the southeast region of the United States. The course establishes its roots in service learning based on the symbiotic relationship between the PTs and middle and high school students. For example, the PTs provide free tutoring for students to help them improve their mathematical skills, while the students provide real-world teaching experience for the PTs to practice their techniques and differentiation strategies.

\section{See Blue Mathematics Clinic}

The See Blue Mathematics Clinic course began in Spring 2011 as a free support for students who struggle in mathematics at the middle and high school levels. The course, which is 15 weeks in length, is broken into two segments. For the first 5 weeks, PTs receive training at the university's campus on how to differentiate instruction to students who struggle in mathematics. Training includes reviewing research literature related to mathematics learning and students who struggle as well as participating in discussions based on these readings. The prospective teachers are also given and practice examples of activities and strategies they can use with students who are struggling to get them engaged in learning. Of these activities and strategies, instructional games are highly emphasized for their academic content and appeal to students [29].

For the remaining 10 weeks, PTs are divided among the partner middle and high schools to implement their newly acquired skills in an informal learning, after-school tutoring environment. Local middle and high schools were chosen in consultation with the local school district. Schools are alternated yearly so that a variety of students and a variety of locations are served. The school principals and the mathematics department chairs of selected schools are contacted and collaborate with the researchers to identify students who would benefit from the tutoring provided by the clinic and to discuss goals of the clinic. Flyers are distributed to make students and their families aware of the tutoring service being offered. Mathematics teachers also help identify students who struggle for targeted recruiting.

The after-school tutoring sessions at both the middle and high schools last $90 \mathrm{~min}$ and are conducted once a week throughout the 10 weeks. Typically in the middle schools, PTs are matched with a small group of students (usually 2-4) to tutor consistently throughout the entirety of the clinic. Students are usually grouped according to grade level in school. Beyond what the students identify themselves as struggling with in mathematics, PTs are given information about the students from their respective mathematics teachers so that the PTs can focus on improving their students' specific weaknesses 
over the course of the 10 weeks. Typically in the high schools, PTs engage in a more "drop-in" tutoring setting where students come to receive help on homework, to prepare for an upcoming test, or to review concepts with which they are struggling. PTs must be prepared to answer questions on a variety of mathematics topics, ranging from prealgebra to calculus.

Throughout the 10 weeks conducted in the schools, PTs are required to reflect on their weekly tutoring sessions as well as a reading reflection that specifically highlights the theory to practice piece via an online discussion board. These reflections culminate in a final reflection paper that allows the PTs to comment on their overall experience in the course and to assess their takeaways from participating.

\section{Participants}

The See Blue Mathematics Clinic consists of enrolled undergraduate and graduate students. The course is required for undergraduate and graduate students who are seeking mathematics certification at the middle or high school levels. It is an elective course in the MS and PhD graduate program.

Fifty-five prospective mathematics teachers who were enrolled in the See Blue Mathematics Clinic course participated in this study through the 2012 (23 PTs), 2013 (19 PTs), and 2014 (13 PTs) iterations. These students ranged in age from 20 to 50.

\section{Data collection}

Data were collected from reflection essays and interviews that were designed to explore the prospective teachers' "lived experiences" [45] and how those experiences informed their understanding of working with students who struggle in mathematics. Prospective teachers participated in a semi-structured interview lasting 15-30 min. The interview protocol examined ways the prospective teachers helped students who struggled better understand mathematics. The interviews were conducted with LiveScribe pens, which also served as audio recorders.

In addition, the PTs completed reflective essays at the end of the service learning course. The essays addressed how the PTs had grown based on their experiences; how they applied their learning to their work with their students; and how they can use the ideas in their future classrooms.

\section{Data analysis}

All interviews were transcribed and a pseudonym was assigned to each prospective teacher. We used an inductive approach to analyze the data, which incorporated systematic methods of managing data through reduction, organization, and connection $[19,31]$. One member of the research team used open coding to develop initial codes [14]. We, then, used the preliminary codes to establish further codes, which were used to code the interview transcripts and reflections. All disagreements were discussed until a consensus was reached. Once a consensus was reached on the codes, the researchers coded the interviews and reflections. After the data were coded, we identified common themes, as well as divergent cases, looking across categories to see if there are underlying patterns to the responses [17]. Once the themes were drafted, two additional mathematics teacher educators reviewed the themes and supporting data to add clarity and 
content validity to the themes. During this review process, important questions were raised about the appropriateness of the themes and whether they were well supported. All discrepancies were resolved during the final development of the overall themes.

Findings

As we examined the research question of how a service learning course prepares prospective mathematics teachers to teach students who struggle in mathematics, five prominent themes emerged from the data. The themes included (a) prospective teachers' perception of students who struggle; (b) prospective teachers' instructional practices; (c) how class experience impacted prospective teachers' content knowledge; (d) prospective teachers' perceptions of the class experience; and (e) how prospective teachers' instruction impacted the knowledge and confidence of the students. The themes are suggestive of how the role of PTs and struggling mathematics students as learners and how critical reflection embedded in authentic experience inform the practice of PTs as they work with students who struggle in mathematics.

\section{Critical reflection: prospective teachers' shift in perception of students who struggle}

At the beginning of the course, some PTs had the misconception that students who struggle in mathematics could not do any mathematics, and that some students were good at mathematics, while others were not. But, the PTs realized one cannot make assumptions about what students can and cannot do. Sixty-three percent of the PTs' reflections stated their students were scared to do mathematics because they feared failure. Therefore, the students tried their best to avoid it. In fact, one PT described how one of his students initially would break down from frustration, refuse to speak, and put his head down on his table. Soon the PTs realized the students relied heavily on the PTs' questions and looked to the PTs to see if their answer was correct. This interaction, which the PTs identified as learned helplessness [1], was difficult for the PTs during the first couple of weeks of working with the students. As the PTs instructed the students throughout the weeks, they realized the students were not what they deemed as "typical" students who struggle. They were not students who struggled at all. Instead, they were students who did not have confidence in doing mathematics. Joseph stated,

I would say that a lot of the students that I worked with, it wasn't necessarily that they were struggling, they just didn't have confidence in what they were doing. Umm, especially for [Rachel] and [Catherine]. They, they [sic] seemed to know what they were doing but, like, to start a problem, especially at the beginning of the tutoring sessions, they'd be like "well I don't know." (Joseph's Reflective Essay, 2011)

The students often second-guessed their answers because they lacked confidence when solving the mathematics problems. The PTs noticed the students were afraid to state their answer, even when it was correct. The students constantly asked the PTs if they were solving problems correctly and wanted affirmation the answer they received on a problem was correct. Many of the students were expecting to fail because they had failed numerous times before in mathematics.

The PTs' conceptions of a student who struggled broadened, and they "realized that struggling learners don't necessarily have to be students that are performing poorly in 
class" (Paul's Interview, 2012). The PTs were surprised when some of the students they worked with stated they really enjoyed mathematics. Students who struggle "are really good students, really smart, there are just some things [that] slow them down or trip them up a little bit" (Mary's Interview, 2012). As the PTs worked with the middle level and high school students, they realized that any student can be a struggling learner at some point in time. Students who struggle just needed more time. "Problems that seem simple to [the PTs], may be difficult for students" (Pamela's Reflective Essay, 2013).

The PTs ascertained why students typically struggle with mathematics. They argued that many students lacked the prior knowledge necessary to successfully engage in the mathematical concepts. The PTs were fully persuaded that "mathematics is a subject that builds," (Talana's 36 Reflective Essay, 2011) and when students do not understand the basics, they were destined to struggle. In essence, the students would give up. Rebecca stated that if students were given the opportunity to learn the "basic building blocks" (Rebecca's Interview, 2013) and learn the how and why behind mathematics, they would not struggle. "It's not necessarily they can't do it, it's that they don't have the tools to do it” (Christina's Interview, 2013). The PTs attributed this deficiency to students' negative experiences in mathematics and poor teaching practices the students may have encountered over the years. Michael elaborated with an example from personal experience:

Teachers, like through high school were very, I won't say dull, I enjoyed the classes because I like to sit and take notes. But, the thing is I don't have to think so much. I think it's why students struggle because you don't have to think so much and you're just taking notes. (Michael's Interview, 2013)

Laurie commented, 'in our readings we learned that the word 'math' or 'mathematics' can produce a strong negative image for many students. This association goes back to past experiences with math or possibly interactions students have with their math teachers" (Laurie's Reflective Essay, 2011). Mathematics, to them, was formulas, rules, and procedures they had to memorize.

Another explanation the PTs suggested as to why students struggle in mathematics was that sometimes students miss a lot of school due to sickness and get behind, and they give up as they try to catch up to learn the material. Many times students just do not know where to begin. For the students who do struggle and were not absent a lot, many of them are intimidated to ask questions in class because they do not want to be embarrassed or reprimanded by the teacher or fellow classmates. So, they sit unknowingly, and fall further and further behind. Stephanie claimed that students who struggle

Just feel as though they can't do it. The preconceptions where they think because I've never gotten it in the past so I'm never gonna get it. Or this kid is great at math because he's blessed with the ability to do it in his head and I'm not. Therefore, I'm not good at math. (Stephanie's Interview, 2012)

Throughout the PTs' experience within the service learning course and individual experiences with students, PTs' perception of struggling mathematics students changed. Structured opportunities for reflection provided a pathway for PTs to question their perception of students who struggle in mathematics in the context of the authentic activity in which PTs engaged. As the PTs worked with the middle level and high school 
students, they discovered that their students persevered in solving problems. In other words, the PTs noticed how their students were willing and wanting to understand. The students did not catch on quickly, but they stuck with it until the problem made sense. Michael commented, "she's coming in and willingly every week wanting to get better, like she's ready, ready to figure out what she's doing, figure out what she's doing wrong, work on-working on getting better and it's just been really cool to see that for me" (Michael's Interview, 2013). They found as they worked with students who were identified as struggling in mathematics that those students $d o$ want to learn and they do care about their learning. They just needed a little extra help and guidance to be successful. Stacy confessed,

Prior to taking this course I believed that a struggling math learner was a student with a major cognitive problem....[that] required truly specialized instruction. What I discovered is something much different. Both through the 5-week preparation period and into the 9-session tutoring clinic I came to discover that the struggling learner is much closer to the average student than not. (Stacy's Reflective Essay, 2011)

Although the PTs recognized the invalid nature of many of their early perceptions prior to working with struggling students, it is important to note the implication of this finding within the PTs future career as educators. Through service learning, PTs are more aware of perceptions of struggling students and are more prepared to recognize those perceptions prior to working with students in their careers.

\section{Situated learning: prospective teachers' instructional practices}

As PTs began learning more about their own perceptions and how to address those in order to become better practitioners, they also learned about the students who struggled in mathematics as learners and how to best address their needs. Instructional practice was one area the PTs found important to consider when working with students who struggle in mathematics specifically. In $64 \%$ of the reflections, the PTs remarked that one of their goals in instructing students who struggle in mathematics was to build their confidence. Before this was possible, the PTs realized the instructional importance of taking time to know their students and build a relationship with them. Marty offered,

I think one of the most valuable lessons I have learned in this class is that no matter how good of a teacher you are, no matter how much knowledge you have in your subject, if you don't make your students trust you and open up to you, it will be very hard to teach them. (Marty's Reflective Essay, 2014)

The PTs realized it was easy for them to come into the sessions with preconceived ideas and stereotypes about their students. Wesley admitted that once he was given the names of two 8th grade boys he was going to work with, he immediately assumed the worse,

My students were going to be loud, obnoxious, and difficult to tutor. This was going to be a long semester. When I finally came face to face with my students I was more than pleasantly surprised. As I got to know who they were and what they liked, I realized these two students were complete opposites of what my mind had conjured 
up. They were respectful, well-mannered, quiet and shy. (Wesley's Reflective Essay,

2012)

Jessica further elaborated, "I had a great time forming a connection with kids and joking around with [them] while still being productive and assisting with their education" (Jessica's Reflective Essay, 2012). The PTs found that once they established a positive relationship with their students, the students were no longer afraid to ask questions. They were not embarrassed when they did not know an answer and when they got a problem wrong. The PTs realized they had to take the time to know their students, learn which instructional methods were effective with their students, and use those instructional approaches during tutoring.

One instructional practice the PTs claimed was the most effective and beneficial with their students was 'math talk.' Prior to working with their students, the PTs read an article by Fuson et al. [23] that focused on math talk, which is when "the teacher and students use discourse to support the mathematical learning of all participants" [26], p. 82). The PTs implemented this strategy with their students, and witnessed huge rewards. They found during math talk they could determine students' mathematical understandings and misunderstandings. The PTs also used math talk to help them differentiate their instruction when they worked with students who were on different levels. The PTs stated math talk provided insight on how their students were making sense of the mathematics, and they used it as a valuable resource for their students to learn from their peers.

The PTs cited the implementation of mathematical games was another beneficial instructional practice. Games provided opportunities for students to think about and understand mathematical concepts. Amber stated, "I came to realize that interesting math games help students pick up on concepts a little better, as well as keeping them engaged" (Amber's Interview, 2012). The PTs remarked that they intended to use mathematics games in their future as a mathematics teacher because they were not only motivating and interactive, but the students also "really get something out of it" (Bret's Reflective Essay, 2011). Jude thought flashcards was a great mechanism to engage his students, but quickly realized he lost his students' attention because the flashcards were “overkill and boring" (Jude's Reflective Essay, 2011). From this point, Jude recognized he had to prepare activities that were not only engaging, but deepened his students understanding of mathematics. Brian stated,

I found that instructional games not only helped students use their prior knowledge and skills, but also kept them involved, engaged and excited about the game and asked to play it again several times throughout the rest of the sessions. (Brian's Reflective Essay, 2014)

Alex further explained,

I have learned that games are much better for keeping struggling learners focused than worksheets or paper activities. It seems that by keeping them active they are much more attentive to the learning process. I think that this is why both of these girls have a problem with completing worksheets for homework when they are on their own. (Alex's Reflective Essay, 2011). 
Amber offered, "In the future, in my own classroom, I will remember to incorporate a variety of strategies, including instructional games, perhaps leaving the teaching modeling and lecture as only a supplementary strategy" (Amber's Reflective Essay, 2012).

Another instructional practice the PTs found themselves engaging in repeatedly was "sitting on their hands." During the first 5 weeks of instruction, the instructors emphasized that many times the PTs would be asked to sit on their hands to refrain from working the problems for the students. During the tutoring sessions, the instructor encouraged the PTs to stop writing during the sessions; this forced them to work on their questioning strategies. Nikki stated, 'I found myself being the 'helicopter tutor' hovering over my students, taking the pencil, and showing them how to do everything step by step" (Nikki's Reflective Essay, 2012). The PTs realized how easy it was to do the work for the student and not have the students think through the mathematics.

Putting down my pen also made me a more effective teacher. Since the student had to write for themselves and not just passively shake their head yes or no, I was able to see more clearly what a student was having trouble with and whether or not they were learning the concepts as the sessions went on. (Megan's Reflective Essay, 2014).

Talana voiced a deep love for mathematics and feelings of having a natural inclination to solve the problems, but admitted to helping students too quickly and not providing adequate time for the students to productively struggle with the mathematics.

I jump in too quickly at times, and don't let the student go ahead and make the mistakes, look at the answer and analyze to decide whether that particular answer is feasible. When we as teachers do this, we are often hurting our students in the long run. (Talana's Reflective Essay, 2011)

Twenty-six percent of the PTs claimed the most challenging aspect of working with the students was not picking up a pencil during the session, but they learned a lot about their students' understanding using this instructional technique.

The PTs had an opportunity to implement a variety of instructional practices with their students ranging from Concrete/Representational/Abstract to teaching mathematics problems in authentic contexts to pushing the students to think by answering a question with a question. The PTs realized that not all of the students they will teach have an Individualized Education Program (IEP) or a 504 plan. However, they need to be prepared to use different instructional strategies to meet the needs of all their students. Additionally, PTs learned these instructional strategies may not be appropriate to plan prior to meeting and learning the unique needs of each of their students.

The PTs recognized the importance of being flexible and always having a backup plan in mind in case something unexpected happens. The PTs stated they became more confident in their teaching abilities throughout the course. They mentioned they learned valuable teaching strategies, such as math talk and approaching concepts in multiple ways, which they plan to use when they are a teacher. As the PTs instructed their students, they reflected on the importance of drawing connections among mathematical ideas. 
Connections that seem obvious to me might not be to students and especially not to struggling learners. I was also glad to be reminded that mathematics is not just something we do in school or something that helps us solve problems, but is also a way of communicating thoughts and ideas. (Ruth's Reflective Essay, 2012)

The PTs not only felt more confident in their teaching, but they also stated they gained greater insight on how to teach. In other words, they contend they have a better ability to notice why students are struggling and ways to effectively teach them as a result of their tutoring experience. Jessica mentioned working with a student who lacked confidence and who would put her head on the table as the PT tried to explain how to solve the problem. Jessica admitted to becoming very frustrated with the student, and noticed that the student picked up on the frustration because the student asked if she was upset with her for not understanding the problem. This experience helped Jessica realize that it is important to be aware of her tone and body language when teaching. Jessica reflected, "if the student thinks that I am mad at them for struggling, this could make them feel anxious and scared to try anything on their own" (Jessica's Reflective Essay, 2013). Jessica admitted being initially embarrassed, and explained that she needed to be her student's "biggest fan" and honestly believe the student can learn mathematics.

For many of the PTs, this was the first time they had the opportunity to work closely with students, and they did not realize students could actually be in the same class and have different understandings. Thirty-eight percent of the PTs mentioned the challenges of working with multiple students. One student is missing "THIS content and one is missing THAT skill" (Sarah's Reflective Essay, 2013). Although Rodney claimed he was good at explaining mathematical concepts, he realized after working with his students that there is more to teaching than being able to explain.

You need to have a plan before you go in; but you also need to know what that plan is based on. Like you need to know what the readings say and how to speak to your students. Some of the words I used kinda confused the students, and what I was saying wasn't actually correspond[ing] to what I was showing. You need to almost run through the lesson before you do it, like think about what you are going to say and what you are going to do; not just plan the activity, actually plan exactly how you are going to do the activity. (Rodney's Interview, 2014).

The PTs expressed the importance of going through the lesson prior to teaching it to students. The PTs stated that going through the lesson helped to make sure the correct mathematical language was used in the explanations and it provided further understanding of how the activity that was planned was going to be implemented.

In addition, the PTs realized the value of differentiating their instruction. Raquel noted,

You don't really think about having to teach students differently depending on where they are in their educational careers, based on if they are a really bright student, you will have to teach in a different way to a really bright student than you would to a struggling learner. And it was hard enough teaching one struggling student. I don't know how I'm going to do it in a classroom with 10 of them plus students at other levels too. But this class definitely helped prepare me for that. (Raquel's Interview, 2012) 
The PTs articulated that although they were there to help the students who were struggling, $62 \%$ recognized they themselves were the benefactors of the experience. In preparation for their careers, the PTs learned that instruction does not just entail the material being taught. Effective instruction specializes in meeting the needs of the students. In fact, the PTs saw the benefit of not teaching in isolation.

The biggest thing that I discovered is how much teachers rely on their peers. I thought that every time I went into tutor, I was going to have to come up with a new activity without any outside help. I soon discovered the opposite though. (Teresa's Reflective

Essay, 2012)

PTs shared games, teaching strategies, and perspectives on approaching challenging situations. "We were able to exchange ideas for activities and give feedback to each other about what ideas worked well and what ideas did not" (Kimberly's Reflective Essay, 2013). PTs referenced the value of learning alternative approaches to instruction from their peers as an important part of establishing confidence in their teaching. "[Sharing] our experiences was crucial for the growth of each tutor" (Tiara's Reflective Essay, 2013). "We would compare and contrast how we tackled the clinic and give each other constructive feedback. I tried to gain as much knowledge as I could" (Logan's Reflective Essay, 2011). The PTs valued their classmates as partners in learning and as influential figures in their continued professional growth. Their classmates became a community of professionals and fellow learners.

The PTs collaborated to expand their content knowledge as well as pedagogical knowledge. They sought out their classmates to better serve the students they were tutoring. From this sense of community, the PTs learned their impact was stronger as a group than in isolation. "Of course, these discussions would have been nothing had we not been able to take what we learned into the classroom" (Paula's Reflective Essay, 2011).

\section{PTs as Learners: Prospective teachers' content knowledge}

The majority of the PTs considered themselves as having strong content knowledge in mathematics. They were mathematics majors and were successful in mathematics throughout school. Consequently, many of them figured they would not have a problem working with students on various mathematics subjects. This notion proved incorrect, especially when the PTs worked with students on geometry. Thirty-three percent of the PTs struggled with the mathematical concepts, and they were unsure how to help their students. For example, Yolanda commented,

She whipped out her homework and I realized right away that I was in trouble as her worksheet was covered with circles, arcs, and chords, and that is not quite my strong point. I walked in overly confident that I knew all of the material, yet as soon as I saw circles, I cringed. (Yolanda's Reflective Essay, 2013)

From this experience, the PTs realized they did not know all the content they needed to know to teach. The PTs stated this forced them to expand their knowledge in geometry and pushed them to be a better teacher. Eric stated that this experience caused him to swallow his "pride" and ask others in the room for help. Eventually, he saw this as a good learning experience because he can now solve the geometry problems. The PTs 
discussed that in order to effectively teach mathematical content, one must understand it. Additionally, finding the gaps in their own content knowledge helped them "become a better teacher" (Ruth's Reflective Essay, 2012).

\section{Critical reflection of situated learning: prospective teachers' perceptions of the class experience}

Some PTs initially expressed they did not think they would learn anything new from taking the course. They discussed how they already had experienced tutoring students, and the course was not going to teach them any information they did not already know. But, the PTs realized the class was an invaluable experience, and they learned a lot.

I've learned so much from this course...I've learned how to be very creative with what I do with them; learned how to do exercises and tasks from scratch which I think has helped a lot... I think now I have a good idea and a good basis for when I actually end up teaching. (Derek's Interview, 2014)

The PTs commented that they were now more confident working with students who struggle in mathematics. Typically, they were comfortable working with more advanced students where the mathematics connections were easier for them to make. But, after this class, many of the PTs confirmed they "feel more confident to effectively work with struggling learners, particularly ones who are incredibly behind in their studies" (Michelle's Reflective Essay, 2012). The PTs reflected that prior to taking the course, they thought they would not be successful helping a student who struggled, but the class provided them with specific strategies to try with their students to make them successful. In fact, some of the PTs stated they were really nervous when they started the course, but at the end of the semester they were confident in their teaching abilities. "I have walked into this clinic with no experience what-so-ever, but I will be walking out with a wide variety of experience and useful knowledge from myself and my peers" (Gwyn's Reflective Essay, 2011). Moreover, the PTs expressed that the class provided them with "valuable insight into the mind of a struggling learner in mathematics, and made me not only a better tutor, but also a better teacher" (Andrea's Reflective Essay, 2014).

The PTs were asked to reflect and connect the theories they read about during the first 5 weeks of class to their instruction during tutoring the last 10 weeks of class via focused reflections on the online classroom platform. Jared confessed that he did not see the purpose of the readings and discussions and how they were significant to teaching and working with students. The PTs admitted they really did not understand what the readings were about. But, "after tutoring for 10 weeks, I now see connections between readings and my sessions" (Jared's Reflective Essay, 2014). Rodney expressed,

In the beginning when we were reading all of that I've always felt that whatever you read in school that's theory, but then when you actually try it, it doesn't always work. I think what I gained most from those readings was actually later when I got home and I wrote the reading reflection and then when I think about what I did I realized that I was actually doing a lot of stuff that was in the readings. (Rodney's Interview, 2014)

The PTs found the service learning course provided them with richer experiences and opportunities. For example, Jesse stated, 
Tutoring the students this semester greatly has aided my growth as a teacher. I learned things about myself that I could never have learned through simple observations. Witnessing first-hand which strategies and games worked well and which ones didn't helped me gain insight into effective running a classroom. The students taught me just as much as I taught them, if not more. (Jesse's Reflective Essay, 2013)

Similarly, Leslie noted,

I got a lot more out of this class than I did my actual practicum where I was in the classroom teaching lessons and things like that because, I mean, it's just more-we focus ON the students and how they're able to learn and how am I supposed to teach them. (Leslie's Interview, 2013)

The See Blue Mathematics Clinic gave the PTs an "understanding of the material that a textbook could never give" (Ella's Reflective Essay, 2012), and helped them develop their "voice as a mathematics educator" (Derek's Reflective Essay, 2011).

\section{Students who struggle in mathematics as learners: prospective teachers' instruction impacted the knowledge and confidence of the students}

As PTs were learning how to be effective teachers, the students they were tutoring deepened their mathematical content knowledge and their confidence in mathematics increased as well.

After about 4 or 5 sessions with [my student], he told me that his math grades were improving. He had a middle $C$ when I started with him and he told me last week [9 weeks later] that his math grade is a 95. I asked him why did he think it was better and he said it was actually because he was putting in more effort than before.

(Amanda's Reflective Essay, 2012)

Seventy-three percent of PTs witnessed improvement in their students' mathematical understanding, and the students did not readily give up on solving a mathematical task. They became more and more confident in their mathematical thinking. For example, Josh worked with his student on special right triangles. When the student struggled to identify the sides, Josh had the student look around the classroom for support, and the student was able to distinguish between the two right triangles that half the room formed. The student made the connection that when two right triangles share a diagonal, a square or rectangle is formed. After the student visualized the content, she proclaimed, "This is so easy! I can't believe that I didn't get this before! This is easy!” (Josh's Reflective Essay, 2011). More importantly, the PTs witnessed that their students were more willing to talk through how they solved mathematical problems. The PTs stated their students knew a lot more mathematical concepts at the end of the clinic than they did at the beginning of the clinic. Caitlin mentioned,

Over the course of the semester, I saw a young man go from being a struggling geometry student to a mathematics student of tremendous knowledge and caliber. I am incredibly proud that [the student] not only passed his final, but gained knowledge that can help him down the road. He grasped proofs more clearly, and this will continue to help him in both current and future geometry classes. (Caitlin's Reflective Essay, 2011) 
Another student successfully passed her first semester midterm. Every week the PT "noticed improvements in her mathematical ability, thinking, and her own confidence. She became less focused on memorizing math formulas and started to understand the underlying concepts that make up Geometry" (Paige's Reflective Essay, 2011). The PTs were very excited to witness improvement in their students' mathematical knowledge and confidence solving mathematics problems. The students began asking for more challenging problems to work on and answering more and more questions. One student showed her tutor her triangle test, which she scored an A. Leslie identified that the student she worked with had learned helplessness, and she found herself constantly reassuring the student that she could do the work even after her student repeatedly said she did not know. Leslie kept trying to help her realize she could do the mathematics. After a few sessions the student did "realize[d] she can do the harder stuff in math" (Leslie's Reflective Essay, 2012). Destiny spoke to her student's teacher, who reported that since working with her, the student's confidence level significantly increased which correlated with a $10 \%$ increase in the student's overall grade. The PTs were extremely proud of their students. "I don't know, they were just like, 'my kids.' I came back each week to see them and they had improved so much. I don't know, I don't know how to describe it. It's like a wonderful feeling" (Destiny's Interview, 2012).

\section{Conclusion}

The purpose of the See Blue Mathematics Clinic was to give PTs seeking certification in mathematics specific instruction and an authentic experience with students who struggle with mathematics via a service learning course. Overall, this study highlighted positive effects of the service learning experience for the PTs. In particular, involvement in the See Blue Mathematics Clinic service learning course indicated positive changes in the PTs' perception of students who struggle in mathematics, improvement in their content knowledge, and overall confidence in working with students, especially those who struggle. Additionally, the service learning experience had a notable positive influence on PTs' instruction, especially in using differentiated instruction, which included, but was not limited to, the use of personalized learning and games. These positive effects are likely rooted in the fact that many of the PTs worked in mathematics content areas that challenged them as tutors and they had to rely on the research-based methods of instruction to effectively reach some of the students who were struggling. The informal learning environment of this service learning course simulated a situation where the tutors were able to practice instructional methodologies in real, authentic, contextualized situations. All of the PTs who have participated in the See Blue Mathematics Clinic course cited it as the most beneficial learning experience in their program thus far.

It was a very positive experience overall both for me and them. They got some one on one time and some exposure to applications of mathematics that they don't necessarily get in the classroom. They had a lot of hands on activities that really immersed them in the mathematics instead of just doing worksheets and things like that over and over. And I think it was also beneficial for me (Jackson's Interview, 2013)

With standards and standardized testing expectations rapidly changing, schools and their students need all the help they can get. Additionally, universities need to find new 
ways to give their PTs additional learning experiences that give them additional work with students. Forming mutually, reciprocal partnership between university and school districts for service learning courses is one way to help address today's educational needs.

The findings of this research can be considered to create more meaningful field experience opportunities for prospective mathematics teachers. Allowing PTs an opportunity to participate in service learning can assist in developing educators that are better equipped to help students who struggle in mathematics. Part of the help that PTs gained through the service learning experience involved the instructional strategies that were practiced, discussed, and ultimately implemented during the tutoring session. Doing so provided a structure for the PTs to engage in positive and productive mathematical interactions [36] with the students they tutored. "The knowledge that secondary teachers in training can gain through peer tutoring during their university careers is transferable and ultimately helpful" [5], p. 28). Further, the positive impact of reflection and collaboration on the engagement and practice of PTs in the tutoring experience reinforced recommendations for designing service learning experiences, or field experiences in general [12, 27, 35, 36, 38, 40].

Although this study highlighted the benefits and outcomes of a service learning course for PTs, further research is needed to examine the experience of the students who struggle in mathematics within this type of authentic environment. In addition, research could be conducted on the aspects of agency that were not explicitly addressed through the themes in this study within the context of how service learning experiential experiences inform PTs future teaching practices.

\section{Authors' contributions}

CJ and MMS designed and coordinated the study overall and the overall draft of the paper. CJ, MMS, MC, SA, KP, EC, MW, and TR carried out the interviews for the data collection. MMS and CJ taught versions of the course and collected the course assessments for the data. SA, KP, AD, EC, MW, and TR made substantial contributions to the theoretical framework and literature review. All authors coded the interviews and came to a consensus on the codes and resulting themes together. All authors made substantial contributions to the written results. CJ and MMS made substantial contributions to the conclusion. All authors read and approved the final manuscript.

\section{Author details}

${ }^{1}$ School of Education, lowa State University, 1688 Lagomarcino Hall, Ames, IA 50011, USA. ${ }^{2}$ University of Kentucky, Lexington, USA.

Competing interests

The authors declare that they have no competing interests.

Ethics approval and consent to participate

All prospective teachers participating in the current study submitted a signed informed consent form.

Funding

The material is based upon work supported, in part, by the National Science Foundation EPSCoR Track 3 award number 1348281, National Science Foundation Research Experiences for Undergraduates award number 1156848, and Kentucky Center for Mathematics award number 2012-599.

\section{Publisher's Note}

Springer Nature remains neutral with regard to jurisdictional claims in published maps and institutional affiliations.

Received: 18 April 2016 Accepted: 13 October 2017

Published online: 20 April 2018 
2. Allsopp, D.H., Kyger, M.M., Lovin, L.H.:Teaching mathematics meaningfully: Solutions for reaching struggling learners. Paul H. Brookes Publishing Co., Inc, Baltimore (2007)

3. Alsup, J., Conard-Salvo, T., Peters, S.J.: Tutoring is real: the benefits of the peer tutor experience for future English educators. Pedagogy $\mathbf{8}(2), 327-347$ (2008)

4. Anderson, J.: Service-learning and teacher education. ERIC Digest. http://www.ericdigests.org/1999-1/service.htm (1998). Accessed 14 Sept 2015

5. Anderson, J.B., Erickson, J.A.: Service-learning in preservice teacher education. Acad. Exch. Q. 7(2), 111-115 (2003)

6. Anderson, J.B., Swick, K.J., Yff, J.: Service-learning in teacher education: Enhancing the growth of new teachers, their students, and communities. American Association of Colleges for Teacher Education, Washington, DC (2001)

7. Baer, J., Russomano, A.T.: An intensive sophomore field experience for preservice teachers. Education 116(3), 432 (1996)

8. Baldwin, S.C., Buchanan, A.M., Rudisill, M.E.: What teacher candidates learned about diversity, social justice, and themselves from service-learning experiences. J. Teach. Educ. 58(4), 315-327 (2007)

9. Bedwell, L., Hunt, G.: Perceptions of a middle level field experience by pre-service high school teachers. High Sch. J. 80(3), 210-214 (1997)

10. Brannon, D., Fiene, J.: The effect structured participation experiences have on pre-service teachers' preparedness to teach reading. Education 134(2), 185-194 (2013)

11. Buchanan, A.M., Baldwin, S.C., Rudisill, M.E.: Service learning as scholarship in teacher education. Educ. Res. 31(5), 28-34 (2002)

12. Butler, M.: Learning from service-learning. Primus $\mathbf{2 3}(10), 881-892$ (2013)

13. Cone, D., Harris, S.: Service-learning practice: developing. Mich. J. Community Serv. Learn. 3, 31-43 (1996)

14. Corbin, J.M., Strauss, A.: Grounded theory research: procedures, canons, and evaluative criteria. Qual. Sociol. 13(1), 3-21 (1990)

15. Creswell, J.W: Research design: quantitative, qualitative, and mixed method approaches, 4th edn. SAGE Publications Inc., Thousand Oaks (2014)

16. Davis, T.M., Bianchi, A., Maring, G.H.: Service-learning for teacher preparation programs in rural areas. In: Anderson, J.B., Swick, K.J., Yff, J. (eds.) Service-learning in teacher education: enhancing the growth of new teachers, their students, and communities, pp. 116-125. AACTE, Washington, DC (2001)

17. Delamont, S.: Fieldwork in educational settings: methods. Pitfalls and perspectives. Falmer, London (1992)

18. Denzin, N.: Interpretive interactionism. Sage, Newbury Park (1989)

19. Dey, l.: Qualitative data analysis. Routledge, New York (1993). https://doi.org/10.4324/9780203412497

20. Everhart, B., McKethan, R.: Preservice teachers' reflections on their home-school clinical teaching experience: evidence to support an alternative field experience for teacher educators. Phys. Educ. 61(4), 177-185 (2004)

21. Feiman-Nemser, S.: From preparation to practice: designing a continuum to strengthen and sustain teaching. Teach. Coll. Rec. 103(6), 1013-1055 (2001)

22. Felton, M.D., Koestler, C.:"Math is all around us and... We can use it to help us": teacher agency in mathematics education through critical reflection. N. Educ. 11(4), 260-276 (2015)

23. Fuson, K., Kalchman, M., Bransford, D.: Mathematical understanding: an introduction. In: Donovan, M.S., Bransford, J.D. (eds.) How students learn: mathematics in the classroom. Committee on how people learn, pp. 217-256. The National Academies Press, Washington, DC (2005)

24. He, W., Means, T., Lin, G.Y.: Field experience tracking and management in teacher development programs. Int. J. Technol. Teach. Learn. 2(2), 134-147 (2006)

25. Hixon, E., Hyo-Jeong, S.: Technology's role in field experiences for preservice teacher training. J. Educ. Technol. Soc. 12(4), 294-304 (2009)

26. Hufferd-Ackles, K., Fuson, K.C., Sherin, M.G.: Describing levels and components of a math-talk learning community. J. Res. Math. Educ. 1, 81-116 (2004)

27. Hung, D., Lee, S.S., Lim, K.Y.: Authenticity in learning for the twenty-first century: bridging the formal and the informal. Educ. Tech. Res. Dev. 60(6), 1071-1091 (2012)

28. Jackson, C., Taylor, C., Buchheister, K.: Bingo! Select games for mathematical thinking. Math. Teach. Middle Sch. 18(7), 424-429 (2013)

29. Jackson, C., Mohr-Schroeder, M.J., Little, D.L.: Using informal learning environments to prepare pre-service teachers. Teach. Educ. Pract. 27(2/3), 445-463 (2014)

30. LaMaster, K.J.: Enhancing preservice teachers field experiences through the addition of a service-learning component. J. Exp. Educ. 24(1), 27-33 (2001)

31. LeCompte, M.D.: Analyzing qualitative data. Theory into practice 39(3), 146-154 (2000)

32. Lester, J.N., Scherff, L., Paulus, T.M.: The ideological dilemmas inherent in informal learning spaces: a discourse analysis of pre-service teacher talk. Qual. Rep. 20(6), 830-846 (2015)

33. Lincoln, E., Guba, l.: Naturalistic inquiry. Sage, Newbury Park (1985)

34. Liu, K. Y.: Enhancing prospective teachers' critical reflection in the ePortfolio environment. Ph.D. thesis, The University of Wisconsin-Madison (2011)

35. Maddrell, J.: Service-learning instructional design considerations. J. Comput. High. Educ. 26(3), 213-226 (2014)

36. McDonald, M., Kazemi, E., Kelley-Petersen, M., Mikolasy, K., Thompson, J., Valencia, S.W., Windschitl, M.: Practice makes practice: learning to teach in teacher education. Peabody J. Educ. 89(4), 500-515 (2014)

37. Meredith, C.: Applied learning in teacher education: developing learning communities among pre-service candidates and urban elementary schools. J. H. Resour. Adult Learn. 6(2), 80-85 (2010)

38. Myers, C., Pickeral, T.: Service-learning: an essential process for preparing teachers as transformational leaders in the reform of public education. In: Erickson, J., Anderson, J. (eds.) Learning with the community: concepts and models for service-learning in teacher education, pp. 13-41. American Association for Higher Education, Washington, DC (1997)

39. Prasertsang, P., Nuangchalerm, P., Pumipuntu, C.: Service learning and its influence on pre-service teachers: a study of social responsibility and self-efficacy. Int. Educ. Stud. 6(7), 144-149 (2013) 
40. Root, S.C.: School-based service: A review of research for teacher educators. In: Erickson, J., Anderson, J. (eds.) Learning with the community: concepts and models for service-learning in teacher education, pp. 42-72. Am. Assoc. High. Educ., Washington, DC (1997)

41. Rupert, N.: Impact of service-learning in an undergraduate middle school principles and practices class. In: Jagla, V.M., Erickson, J.A., Tinkler, A.S. (eds.) Transforming teacher education through service-learning, pp. 123-144. Information Age Publishing, Charlotte (2013)

42. Sanders, P.: Phenomenology: A new way of viewing organizational research. Acad. Manag. Rev. 7(3), 353-360 (1982)

43. Smith, M.D.: An examination of a generic field experience from a physical education perspective. Phys. Educ. 50(3), 151 (1993)

44. Swick, K.J.: Service-learning in teacher education: building learning communities. Clear. House 74(5), 261-264 (2001)

45. Van Manen, M.: Researching lived experience: human science for an action sensitive pedagogy. State University of New York Press, New York (1990)

46. Wade, R.C.: Developing active citizens: community service learning in social studies teacher education. Soc. Stud. 86(3), 122-128 (1995)

47. Ward, K., Wolf-Wendel, L.: Community-centered service learning moving from doing for to doing with. Am. Behav. Sci. 43(5), 767-780 (2000)

48. Zeichner, K:: Rethinking the connections between campus courses and field experiences in college- and universitybased teacher education. J. Teach. Educ. 61, 89-99 (2010)

\section{Submit your manuscript to a SpringerOpen ${ }^{\circ}$ journal and benefit from:}

- Convenient online submission

- Rigorous peer review

- Open access: articles freely available online

- High visibility within the field

- Retaining the copyright to your article

Submit your next manuscript at $>$ springeropen.com 